\title{
A constituição da lógica professoral: um estudo sobre saberes e práticas docentes franco-brasileiras
}

\author{
Gabriela Valente ${ }^{1}$ \\ ORCID: 0000-0003-0737-2432
}

\section{Resumo}

O objetivo deste artigo é propor uma nova forma de compreensão da atividade docente a partir do termo lógica professoral, ou seja, um princípio de justiça composto por saberes docentes e mobilizado pelos professores em suas práticas profissionais. A elaboração desse conceito teve sua inspiração na sociologia pragmática e nos seguintes questionamentos: quais seriam as lógicas de ação que orientam as condutas dos docentes? As mesmas lógicas de ação são utilizadas por docentes em contextos socioculturais diferentes? Seria possível encontrar semelhanças entre os princípios de justiça de profissionais franceses e brasileiros? Para responder a essas questões, foram realizadas observações de campo e 36 professores brasileiros e franceses foram convidados a descrever situações profissionais em entrevistas semidiretivas. A análise de situações ligadas às atividades reais dos docentes revela que, embora haja uma pluralidade de lógicas, existe uma tendência para o uso de uma lógica cívica na França e de uma lógica liberal no Brasil. A discussão desse resultado evidencia que as lógicas de ação estão circunstanciadas a critérios de justiça privilegiados nos contextos nacionais. Contudo, foi possível concluir que, mesmo em configurações socioculturais diferentes, existem saberes profissionais compartilhados pelos docentes nos dois países, que são traduzidos em princípios de justiça e compõem uma lógica de ação professoral.

\section{Palavras-chaves}

Práticas docentes - Lógica professoral - Profissionalidade - Educação comparada Socialização profissional docente.

1- Universidade Jean Jaurès, Toulouse, França. Contato: gabriela.abuhab.valente@gmail.com 


\section{The formation of teaching logic: a study on Franco- Brazilian teaching knowledge and practices}

\section{Abstract}

The purpose of this article is to propose a new way of understanding teaching based on the term teaching logic, in other words, a principle of justice comprising teaching knowledge and mobilised by teachers in their professional activities. The drawing up of this concept was inspired by pragmatic sociology and by the following questions: what would the action logics be that guide the conduct of teachers? Are the same action logics deployed by teachers in different sociocultural contexts? Would it be possible to find similarities between the principles of justice of French and Brazilian professionals? To answer these questions, field observations were carried out and 36 Brazilian and French teachers were invited to describe professional situations in semi-structured interviews. The analysis of scenarios linked to teachers' real activities reveals that although there is a plurality of logics, there is a tendency to use a civic logic in France and a liberal logic in Brazil. The discussion of this result demonstrates that action logics are limited to privileged justice criteria in national contexts. Nevertheless, it was possible to conclude that, even in different sociocultural settings, there is professional knowledge shared by teachers in both countries, which are translated into principles of justice and comprise a teaching action logic.

\section{Keywords}

Teaching practices - teaching logic - Professionalism - Comparative education - Teacher professional socialisation.

\section{Introdução}

As discussões apresentadas neste artigo foram motivadas por resultados de uma pesquisa doutoral ${ }^{2}$ e uma pesquisa internacional denominada "Religião, discriminação e racismo no espaço escolar" 3,4 , coordenada por Françoise Lantheaume (Université Lumière Lyon 2) e financiada pela DILCRAH ${ }^{5}$. A pesquisa de caráter pluridisciplinar conta com integrantes brasileiros, franceses, canadenses e suiços. A questão das práticas docentes é o tema central deste estudo, que busca compreender como os professores agem mediante situações que são ordinárias e, ao mesmo tempo, pouco previsíveis.

\footnotetext{
2- A pesquisa doutoral contou com o financiamento da Fapesp, número do processo 2015/22243-8. Ver referências em Valente (2019).

3- Site da pesquisa: https://redisco.hypotheses.org/

4- A pesquisa seguiu as normativas da resolução CNS 510/2016 referentes à ética na pesquisa com seres humanos e contou com o termo de consentimento livre e esclarecido assinado por todos os docentes entrevistados.

5- Délégation Interministérielle à la Lutte Contre le Racisme, l'Antisémitisme et la Haine anti-LGBT (Delegação interministerial de luta contra 0 racismo, antissemitismo e ódio anti-LGBT). A tradução deste artigo em inglês foi financiada igualmente por essa instituição.
} 
Partindo da sociologia do trabalho, um de nossos pressupostos é que a aprendizagem da profissão docente se efetiva principalmente no momento da atividade profissional, com os pares mais experientes e de forma interpessoal, a partir das situações de trabalho, nas situações de trabalho e pelas situações de trabalho (FRANCQ, 1996). É um processo que possui uma intenção social de valorizar a profissão, estabelecendo alguns conhecimentos específicos da ocupação (WITTORSKI; BRIQUET-DUHAZÉ, 2005). Tardif e Lessard (1999) evidenciam o caráter sincrético da profissão docente, no sentido de que a ação cotidiana é composta por uma amplidão de conhecimentos e de savoir-faires. Assim, entendemos que saberes e práticas docentes são duas facetas da mesma moeda, ou seja, os saberes docentes são mobilizados nas práticas docentes e, ao mesmo tempo, as práticas docentes permitem a construção de novos saberes profissionais.

Dentre os muitos saberes docentes, aquele que destacamos para esta reflexão é o saber reagir de forma astuciosa diante das imprevisibilidades das situações escolares. Efetivamente, quando um adulto está com um grupo de crianças em uma sala de aula, durante um período de aula, não é possível saber o que pode acontecer nesse espaço e tempo, uma vez que se trata de interações sociais. Desse modo, questões relativas ao tema da pesquisa internacional, a saber, a religião, a discriminação e o racismo que, por vezes, tocam a sensibilidade dos indivíduos, podem surgir de forma imprevisível a partir da discussão de um conteúdo, de uma atualidade midiática ou política, de um debate entre os alunos, na relação entre pais e professores etc. Nesse sentido, nos questionamos sobre quais valores estão por trás dos saberes e das práticas docentes em situações profissionais ${ }^{6}$. Para fundamentar essa questão teoricamente, utilizamos a sociologia pragmática.

\section{A prática docente a partir de princípios de justiça}

Partindo das teorias da filosofia política, os autores da sociologia pragmática (NACHI, 2012) identificam princípios de justiça baseados em uma concepção moral, que seriam mobilizados nas condutas humanas. Para compreender a mediação simbólica e axiológica entre a concepção moral e a ação, os autores fazem uso do conceito de cidades/ cités (BOLTANSKI; THÉVENOT, 1991). As cidades/cités seriam padrões de justiça que precedem os atores e que lhes permitem um posicionamento prático. Assim, construídos coletivamente, os princípios de justiça orientam a conduta humana a partir de uma apropriação individual.

As situações envolvem um "conjunto de interações entre pessoas e entre elas e os objetos” (LANTHEAUME, 2008, p. 17) e favorecem a compreensão dos princípios de justiça dos atores pesquisados a partir de diferentes regimes de ação. 0 regime pelo qual este estudo se interessa é, principalmente, o regime de justiça, no qual estão envolvidos objetos e pessoas que buscam referências para justificar ações que consideram justas, além de denunciar injustiças.

Ao estimular uma ação, os critérios de justiça e do bem comum mobilizam determinados valores dos atores que não são sempre coerentes, mas para a análise desses princípios, a sociologia pragmática sugere tipos ideais com a finalidade de

6- Sem incluir situações envolvendo a relação entre as práticas docentes e a aprendizagem dos alunos. 
melhor compreendê-los. Esses tipos ideais são denominados de lógicas de ação, que permitem analisar a ação humana levando em conta a relação do ator com os objetos e com o sentido de justiça. As lógicas de ação fazem referência aos modelos de cidades/ cités criados por Boltanski e Thévenot (1991) e são fundamentadas em uma determinada concepção de bem comum.

Assim, podemos identificar os princípios de justiça e as lógicas de ação por meio da descrição e da justificação fornecidas pelo ator para explicitar sua forma de agir em determinada situação. Desse modo, a prática em si não é necessariamente compartilhada, mas a finalidade da ação e a forma de se engajar na atividade respeitam convenções do grupo social, pois tratam-se de critérios que organizam o mundo social e político dos atores e que orientam as ações suscetiveis de produzir um efeito desejável. Assim, Boltanski com Thévenot (1991) e Chiapello (1999) sugerem sete cidades/cités.

0 coletivo, o universalismo, o interesse geral, a igualdade de direitos e o respeito às regras do sistema democrático fazem parte da cidade/cité cívica que pressupõe uma lógica de ação homônima. A lógica cívica é uma lógica de ação individual e, ao mesmo tempo, uma lógica política (GAUTHERIN, 2005). 0 respeito à família, aos ritos e às tradições é privilegiado na cidade/cité doméstica. A relação entre os atores, nesse caso, é de proximidade, mas há uma autoridade que precisa ser respeitada, pela sua sabedoria e experiência. A busca pela melhor performance e pela melhor técnica, buscando a eficácia e a produtividade, revelam uma lógica de ação que corresponde à cidade/cité industrial. $\mathrm{Na}$ cidade/cité inspirada prevalecem a criatividade, a autenticidade e a originalidade enquanto princípios. A vocação ou o dom estão presentes. Para os atores, é essencial que essa lógica de ação transgrida as regras em nome de uma espontaneidade. Na lógica mercadológica, a justificação se orienta pelo espírito da competição, sendo o desejo de possuir aquilo que corresponde ao bem comum. A celebridade, o renome, o reconhecimento de uma pessoa pelos seus pares é o que é privilegiado na cidade/cité de opinião. A lógica de ação dentro da cidade/cité conexionista representaria o novo espírito do capitalismo, em que a mobilidade e a capacidade de se ligar em rede para a realização de projetos é o que fundamenta a ação (BOLTANSKI; CHIAPELLO, 1999).

Uma releitura da sociologia pragmática possibilita que Gautherin (2005) acrescente outras duas lógicas de ação que partem de um modelo político (e não filosófico): a lógica de ação liberal sugere o respeito dos direitos individuais, assim, a liberdade de cada ator se sobrepõe à igualdade. A segunda é a lógica comunitária, cujo princípio fundador é o reconhecimento do indivíduo enquanto pertencente a uma comunidade, fazendo a oposição entre o bem comum do grupo contra o bem comum da sociedade moderna.

Os atores escolhem seu modelo de ação a partir de testes com eles mesmos e com os outros na interação social. 0 resultado desse teste contribui para a criação de uma forma de agir, legitimando-a e tornando-a social. A realidade social, por sua vez, dá sentido para as práticas individuais. Compreendemos, assim, que as lógicas de ação são escolhidas reflexivamente pelos indivíduos durante a situação, levando em consideração fatores como: a interação com atores humanos e não-humanos que as compõem, as disposições individuais e os efeitos de socializações anteriores. Dessa forma, o processo de socialização, anterior ao 
momento da situação, é utilizado enquanto um recurso para a seleção da lógica de ação e, por sua vez, os resultados dessa escolha terão efeitos socializadores.

Os estudos da sociologia da justificação a partir de princípios de justiça transformaram a questão inicial nas seguintes indagações: quais são as lógicas de ação que orientam as condutas dos docentes? As mesmas lógicas de ação são utilizadas por docentes em contextos socioculturais diferentes? Seria possível encontrar semelhanças entre os princípios de justiça dos profissionais franceses e brasileiros?

Para responder a essas questões, realizamos entrevistas semidiretivas com dezoito docentes brasileiros e com o mesmo número de professores franceses ${ }^{7}$. Essa ferramenta de pesquisa foi escolhida devido à centralidade da atividade profissional real dos docentes, das suas formas de agir em situações escolares e das maneiras como justificam suas práticas docentes. Durante as entrevistas, os professores foram convidados a relatar situações escolares envolvendo a diversidade social e cultural. As palavras religião, discriminação e racismo não foram mobilizadas em um primeiro momento, com o objetivo de conhecer as categorias próprias dos docentes. As entrevistas semidirigidas foram realizadas individualmente com professores voluntários no espaço escolar.

Além disso, foram realizadas 250 horas de observações de campo em escolas brasileiras e francesas entre os anos de 2016 e 2018. Realizadas em estabelecimentos públicos de ensino, com o acordo dos docentes, as observações seguiram o protocolo da etnografia sociológica, no qual as ações dos atores são compreendidas na relação com outros sujeitos, com o contexto, com a história, com as trajetórias de vida e com os valores de cada indivíduo. 0 diário de campo foi utilizado para anotações nas escolas e, em seguida, para a realização de um registro ampliado. As observações permitiram a realização de um trabalho comparativo, pois não teríamos legitimidade para falar da prática docente utilizando apenas elementos teóricos ou discursivos. Nesse sentido, utilizamos a perspectiva da educação comparada, que não prevê uma comparação item por item, levamos em consideração a complexidade cultural interna e externa dos países e relacionamos diferentes perspectivas para compreender os fenômenos sociais e, mais especificamente, elementos da profissionalidade dos docentes entrevistados.

Seguindo os passos de Boltanski e Thévenot (1991), o objetivo deste artigo é monter en généralité para identificar as lógicas de ação, ou seja, visualizar os dados com o olhar de aviador, buscando o que é generalizável e coletivo a partir dos dados recolhidos. Infelizmente, o espaço de um artigo não possibilita trazer a análise do material e a reflexão. A explicitação dos dados e a análise são objetos de publicações anteriores, assim como a discussão do tema da diversidade social e cultural (VALENTE, 2019).

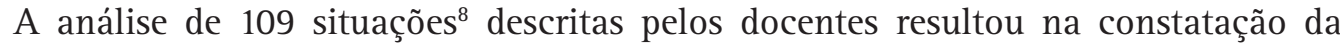
existência de uma pluralidade de lógicas nas situações, mas quando comparamos os dados, percebemos uma tendência da mobilização das lógicas cívica e liberal na prática docente francesa e das lógicas liberal e doméstica na prática docente brasileira. Para discutir esse resultado de pesquisa, o texto segue com uma argumentação sobre a pluralidade

\footnotetext{
7- Mais especificamente, o estudo foi feito na cidade de São Paulo, no Brasil, e na cidade de Lyon, na França. Embora tenhamos consciência da impossibilidade de generalização, optamos por distinguir as duas realidades sociais a partir das nacionalidades.

8- Não foi possível apresentar as situações devido ao limite do artigo, mas elas podem ser consultadas em Valente (2019).
} 
das lógicas. Em seguida, discutimos que essas lógicas não correspondem apenas ao nível microssocial da instituição ou da sala de aula, mas estão relacionadas aos princípios de justiça priorizados nas sociedades em escala macrossocial. Por fim, argumentamos quanto à existência de um critério de justiça próprio à prática profissional docente, o qual denominamos lógica professoral.

\section{Pluralidade das lógicas de ação}

A análise das situações revelou que as lógicas de ação liberal e doméstica se combinam na maior parte das situações escolares brasileiras. Na França, a lógica cívica se torna plural ao se combinar com a lógica liberal. A pluralidade de lógicas de ações nos dois sistemas educacionais é justificada pois:

A escola está irremediavelmente dentro de um universo onde os princípios de regulação são múltiplos e ela deve encontrar uma maneira de regulação que leve em consideração essa pluralidade. 0 compromisso entre os diferentes princípios não pode ser feito em escala nacional. Nesse nível, a exigência é grande: o compromisso deve ser perfeitamente justificado em todos os universos de referência. (DEROUET, 1992, p. 62, tradução nossa).

Segundo o mesmo autor, a pluralidade das lógicas de ação presente nas condutas dos professores depende das particularidades locais, mas também das singularidades das configurações sociais. Os princípios de justiça mobilizados nas práticas docentes são diversos nos casos dos dois países e a negociação permanente e implícita entre os valores plurais resulta em um equilíbrio entre as diferentes lógicas e suas justificativas.

Dentro de um universo complexo de justificação como a escola, cada pessoa é suscetível a participar de uma situação utilizando diferentes referências de justiça e a passar de uma referência de justiça para outra, a fim de se adaptar ao contexto social (DEROUET, 1992). A pluralidade de referências está diretamente ligada à situação vivida pelo docente, mas também aos recursos que ele possui, os quais, por sua vez, são associados às disposições individuais construídas durante sua trajetória de vida e à construção identitária e profissional durante o processo de socialização profissional (DUBAR, 2005). 0 fato de passar de uma lógica a outra não é um incômodo para os docentes, eles o fazem com grande facilidade e habilidade. Isso mostra a plasticidade das ações dos professores ou a facilidade com a qual suas disposições são adaptáveis e as normas profissionais flexibilizadas. Essas características são consideradas aqui como saberes docentes que permitem uma relação pragmática entre os indivíduos e os princípios de justiça, que são mobilizados de acordo com suas necessidades e interesses coletivos para recompor ou criar, a partir de seus saberes, formas de se apropriar das normas profissionais (DUBET, 2014).

\section{Lógicas liberal e doméstica no Brasil}


Embora não haja estudos anteriores que confirmem a prevalência da lógica liberal no campo educacional brasileiro, outros elementos constatam esse resultado. Um deles estaria relacionado à estrutura da sociedade brasileira, que, por ser um Estado do Sul pouco forte (MARTUCCELLI, 2010), responsabiliza o indivíduo pelos seus direitos fundamentais, como saúde e educação. Tendo consciência do esforço individual necessário, o brasileiro aceita, tolera e (re)produz o jeitinho brasileiro, tornando os laços sociais e a relação entre indivíduos mais importantes do que as normas legais. 0 convívio entre injunções legais e uma cultura relacional individualista são traços da complexa realidade brasileira.

Um segundo aspecto relaciona-se com as influências midiáticas norte-americanas e as relações econômicas e políticas com o país, representando o apogeu da lógica liberal reproduzida pelos Estados Unidos. A lógica do self-made man associada à ideia da existência de um mérito individual para ser bem-sucedido é corrente no discurso brasileiro, inclusive dos professores. Em seguida, a lógica liberal proveria aos indivíduos condições de possibilidade para a hibridização das disposições de habitus (SETTON, 2012), pois cada indivíduo se forja por meio das múltiplas e desencontradas referências.

Por fim, um estudo sobre a forma como a laicidade é definida no Brasil (MENARD; VALENTE, 2016) revela a existência de uma lógica liberal manifesta no imaginário dessa configuração social. Assim, a estrutura social e algumas compreensões dos fenômenos sociais impulsionariam uma visão de mundo liberal no Brasil. De forma geral, na fala dos docentes a lógica liberal se manifesta pelo respeito e pela liberdade individual, que justificariam suas formas de agir.

Contudo, a lógica doméstica também foi identificada na ação cotidiana/global, sobretudo a partir da observação de campo. A existência dessa lógica poderia ser explicada pela história da educação brasileira, especialmente no que concerne às lacunas das políticas públicas para a formação e a profissionalização de docentes (GATTI et al., 2019). Além do elemento histórico, identificamos que a preocupação dos docentes brasileiros com o bem-estar e com a escolaridade dos alunos (principalmente dos alunos carentes) gera uma aproximação entre professores e estudantes como uma estratégia docente para garantir a escolaridade dos menores. Tal estratégia pedagógica é explicitada não apenas em conversas com os alunos, mas também no toque terno e nos pronomes de tratamento entre professores e alunos (principalmente os mais jovens), como já fora notado por Paulo Freire (1997) há mais de duas décadas, criando um ambiente familiar.

Quando interrogados sobre suas ações pautadas pela lógica doméstica, os professores geralmente têm dificuldades para justificar essa forma de agir. A ausência de uma explicação para a ação é aqui identificada como um aspecto da naturalização dessa atitude adquirida por meio da socialização profissional. Trata-se de uma conduta profissional incorporada e transmitida aos pares de forma legitimada e acaba propondo um modelo de agir que é visto como o ideal, podendo dar certo quando se estabelece uma mínima distância na relação professor-aluno, mas também pode ter consequências não desejadas, como no caso em que a relação professor-aluno é marcada pelo desafio da autoridade.

Dessa forma, os docentes brasileiros mobilizam principalmente duas lógicas de ação: a liberal e a doméstica. A focalização no indivíduo e a tendência à proximidade das relações estão atreladas a influências sociais das políticas públicas e econômicas não 
apenas voltadas à educação. Em nosso entendimento, os professores buscam estratégias de ação que envolvam conhecimentos provenientes de suas trajetórias de vida e dos saberes construídos em exercício para um agir criativo seguindo os princípios que lhes são caros, como a liberdade individual, o respeito ao outro, a proteção dos alunos, a aprendizagem afetiva e a valorização da educação escolar.

\section{Lógicas cívica e liberal na França}

Derouet (1992) encontrou em suas pesquisas a lógica cívica enquanto lógica de ação privilegiada nas práticas docentes francesas na escola republicana. Segundo o autor, essa lógica foi predominante até que estudos sociológicos começaram a desconstruir a ideia de que a escola seria um meio de ascensão social. A partir desse momento, o debate passa a ser sobre a igualdade de oportunidades, privilegiando o princípio de equidade. Nesse contexto, outras lógicas de ação passam também a ser representadas, criando um universo de justificação complexo. Dessa forma, em paralelo à lógica cívica, o autor identificou as lógicas comunitária, da eficácia (industrial), inspirada e mercadológica, em ordem de frequência (DEROUET, 1992).

0 cenário educativo francês dos anos 1990 passa por uma descentralização e começa a ser representado pela ligação entre o geral e o particular, entre os princípios de ação e a conduta cotidiana local. A associação entre educação e república não é mais tão evidente como era antes desse período histórico, mas a necessidade de um princípio geral continua presente nas práticas docentes para justificar as ações. Contudo, Derouet (1992) não fala em lógica liberal, provavelmente porque esse conceito não é utilizado pelos autores da sociologia pragmática9 ${ }^{9}$. Nós a identificamos como sendo a segunda lógica mais frequentemente mobilizada nas situações descritas pelos docentes entrevistados. Em nossa interpretação, o deslocamento para a lógica liberal seria próprio do contexto histórico-social e da história da profissão que propõe uma valorização do indivíduo como responsável pela sua aprendizagem. Esse deslocamento ocorre, em parte, a partir do debate sobre interculturalidade, uma vez que a lógica liberal seria uma forma de compromisso em que o indivíduo é valorizado e, ao mesmo tempo, possibilita que os docentes encontrem recursos que respondam, de um lado, às leis, às prescrições curriculares e ao universal e, de outro, ao reconhecimento das identidades individuais para gerir as situações (LANTHEAUME, 2007) com o objetivo de facilitar as aprendizagens escolares.

A presença marcante da lógica liberal nas duas configurações socioculturais estudadas poderia ser explicada pela influência do liberalismo e do capitalismo no modelo e nas lógicas escolares de forma global. A partir da lógica economista, a educação se torna um sistema que reproduz as assimetrias sociais e que regula certos mecanismos de socialização, notadamente o político e o ideológico, para a formação de cidadãos conformados (RESENDE, 2005).

9- 0 conceito é usado pela socióloga Gautherin (2005), que utiliza a sociologia pragmática enquanto referência. 


\section{Da lógica de ação individual à lógica de ação contextualizada}

Nos inspiramos nos regimes de engajamento de Thévenot (2001) para a compreensão de que a ação particular de um ator se ajusta ao seu coletivo próximo, ou seja, às pessoas com quem interage a partir de uma determinada lógica ou modelo de ação. Dessa forma, as configurações socioculturais, mesmo estando embebidas em um processo de globalização e de coexistência de diferentes ordens de valores, possuem particularidades e propõem formas socialmente partilhadas de ser e estar em sociedade, ou, nas palavras de Dubet (2014, p. 177), "cada princípio de justiça estrutura um tipo de representação da sociedade”.

Assim, as lógicas de ação representam concepções do bem comum que vão além da ação humana individual. Elas são produzidas e provocam efeitos de socialização particulares em cada um dos contextos sociais, agindo na construção de identidades nacionais. Assim, a mobilização de determinados princípios de justiça não está apenas relacionada com a situação em seu microcosmo e com a interação social e profissional em seu mesocosmo, mas está ligada também a uma forma de socialização nacional que, por meio das suas diferentes instituições socializadoras, oferece princípios de justiça aos seus cidadãos.

Ao identificar o processo de socialização como um espaço plural de múltiplas referências, essas tendências de formas de agir fundamentadas por certos valores são frutos de uma conjunção de esforços pedagógicos entre instâncias socializadoras que trabalham na consolidação de uma maneira de se relacionar com categorias de julgamento legitimadas socialmente. Sem perder de vista o ator, lembramos que cabe ao indivíduo enquanto agente reflexivo, ou seja, aquele que possui uma participação singular na construção da realidade social e na construção de si mesmo, combinar e articular as diferentes referências para dar sentido às suas práticas e experiências sociais.

Entretanto, como o ator raramente conhece realidades nacionais diferentes da sua, os princípios de referência propostos institucionalmente são raramente questionados. Nesse sentido, em situação, a pluralidade de lógicas não deixa de existir, mas a configuração social específica propiciaria uma tendência para a prevalência de uma lógica de ação, mesmo que plural, e para uma socialização particular a cada país estudado.

Dessa forma, a instituição escolar é, junto com outras instituições, mais um instrumento para a transmissão de valores nacionais. As lógicas de ação privilegiadas em cada configuração sociocultural estão presentes na escola e nas ações dos docentes, uma vez que a observação e a reiteração dessas condutas estão dentre as formas de aprendizagem existentes. Efetivamente, não existe uma forma única de ser professor e os diversos pontos de vista podem contribuir para uma riqueza na interpretação do mundo. Dessa forma, a identificação das tendências na prática docente dos professores entrevistados é aqui interpretada enquanto efeito de uma socialização profissional docente, mas também de uma socialização nacional.

Como contra-argumento, destacamos aqui o papel da cultura do estabelecimento escolar. Tal cultura pode representar a possibilidade de que não haja uma correspondência entre a lógica de ação priorizada em situação e a lógica de ação identificada no âmbito nacional. Nos referimos aqui especificamente ao caso de uma escola em que a principal lógica de ação dos 
professores em situação é cívica por conta das condições favoráveis de trabalho, embora em outros contextos escolares no Brasil haja a prevalência da lógica liberal.

Assim, a socialização profissional docente, envolvida no caldo da configuração sociocultural de cada país, concebe a igualdade como o valor privilegiado no sistema educacional francês, caracterizando uma lógica cívica, seguida pela lógica liberal. No sistema educacional brasileiro, a liberdade individual tem maior peso, indicando a prevalência de uma lógica liberal acompanhada pela lógica doméstica. Cabe lembrar que essa generalização é válida para o presente e está submetida a transformações por se tratar de um processo social. Essas tendências não significam que exista uma homogeneidade na forma de agir dos docentes, mas é resultado da busca por acordos sobre normas e práticas em uma profissão que é marcada pela diversidade.

\section{Lógica professoral: parte e parcela da profissão docente}

Os regimes pragmáticos, para Thévenot (2001, p. 7), são instrumentos sociais que "norteiam o envolvimento do indivíduo com o meio social, articulando a noção moral do bem e a forma de ser incluído na realidade” (tradução nossa). As situações analisadas revelam que os docentes compartilham valores e normas que seriam intrínsecos à deontologia docente e que servem para iluminar as tomadas de decisão e guiar os professores em suas ações. Assim, as práticas docentes poderiam ser classificadas enquanto um regime da profissão, mesmo que existam influências de elementos externos no agir do profissional. Esse resultado leva à reflexão sobre a possibilidade da existência de uma lógica de ação própria às situações escolares e às práticas docentes.

As lógicas de ação identificadas na prática profissional dos docentes entrevistados são insuficientes para representar os princípios de referência de justiça presente nos seus discursos. A ordem justa da prática docente, de forma geral, está baseada em uma verdade científica/curricular, racional e crítica e a definição de bem comum está ligada com a universalização do conhecimento para garantir a inclusão social, a escolaridade e a aprendizagem dos alunos. Assim, sugerimos a introdução de uma lógica de ação em que a escolarização é a medida de grandeza, ou seja, é grande aquele que atinge as competências que são requeridas pela escola para se manter na instituição e continuar seus estudos, mesmo que não sejam os melhores alunos. Essa forma de justiça está relacionada com a autonomia racional do conhecimento e com seu acesso universal. Em nossa análise, observamos essas convenções gerais superiores na prática de grande parte dos docentes entrevistados, independentemente de sua nacionalidade, com maior assiduidade nos discursos dos docentes mais experientes.

Nessa lógica de ação ideal, o justo se traduz pela transmissão de uma verdade legitimada pela comunidade científica, levando em consideração as condições de possibilidade de escolarização dos alunos de acordo com suas características sociais e culturais e, por isso, a interação com o aluno é vista de forma positiva. 0 conhecimento é valorizado como forma de garantir a própria liberdade (lógica liberal) e a dos outros, além de promover o debate para a construção de uma sociedade melhor e mais igualitária (lógica cívica). Contudo, a lógica professoral não se resume à associação entre duas lógicas, pois ela acresce, de um lado, saberes próprios à profissão como a gerência da autonomia docente, 
a plasticidade para lidar com o imponderável e o uso de estratégias e ações ajustadas às situações, implicando, por vezes, a mobilização de normatividades intermediárias (LANTHEAUME; SIMONIAN, 2012). Do outro lado, no que concerne à subjetividade dos docentes, acrescentam-se valores democráticos e coletivos, uma benevolência intrínseca da atividade mandatária do docente, relacionada ao dar, ao cooperar, ao reconhecer e ao proteger e valorizar os alunos.

Contudo, é preciso considerar que "não existe dádiva sem a expectativa de retribuição, multiplicação ou legitimação de uma crença [...] e de um poder simbólico" (SETTON, 2012, p. 50). Nesse sentido, a mobilização da lógica professoral, por parte dos professores, estaria relacionada ao reconhecimento da função social da profissão docente e da certificação de que seu trabalho possui um valor para a sociedade, ou seja, enquanto posição social (profissão) e enquanto atividade (transmissão de saberes, valores e sentidos). Desse modo, a lógica professoral é um instrumento socializador que valoriza e legitima a forma escolar (VINCENT, 1994) como monopólio do conhecimento e do sucesso social do indivíduo-aluno a partir da escolarização.

Tal forma de agir seria originária de disposições incorporadas pelos docentes por meio da socialização profissional, que começa em sua escolarização pela observação de seus próprios professores. Não queremos com isso dizer que os processos de socialização profissional docente sejam semelhantes nos dois países, mas as características dos sistemas de ensino moderno, que são identificados no paradigma da forma escolar (VINCENT, 1994), poderiam ser uma justificativa para a valorização de uma lógica de ação professoral similar em dois contextos sociais diferentes, permitindo a imposição da disciplina aos alunos e a argumentação a propósito da existência da escola e da transmissão do saber.

A lógica de ação professoral reafırma uma representação coletiva da educação enquanto Paideia e uma crença na instituição escolar como a solução para problemas sociais. Nesse sentido, essa lógica estaria atrelada ao princípio não apenas de justiça, mas também de coesão que permite ao docente dar sentido às suas práticas individuais em uma realidade educacional moderna, religando uma identidade social e profissional a uma experiência subjetiva e socializadora e identificando a prática docente como um ato político.

Em resumo, as principais características dessa lógica de ação são a benevolência intrínseca à profissão docente, a observação dos alunos enquanto seres sociais em situação de aprendizagem, o reconhecimento das competências intelectuais dos alunos (ZANTEN et al., 2002), a valorização da propagação do conhecimento associada à idealização da educação e a identificação desse princípio de justiça como uma característica da profissão. A lógica professoral representaria um compromisso possível que aliviaria a tensão identificada por Derouet (1992) entre a democratização, a racionalidade e a justiça, de um lado, e o amor e o respeito pela infância, do outro.

\section{Considerações finais}

As práticas e os saberes docentes resultam de uma hibridização de competências e disposições adquiridas durante a trajetória de vida dos professores e de recursos que estão disponíveis na situação profissional, muitas vezes, imprevisível. Contudo, os docentes 
recorrem pouco aos recursos que são impostos, ou seja, que não são criados por eles. A busca de um equilíbrio entre aquilo que é norma e a atividade real faz com que a normatividade intermediária faça parte da atividade deontológica da profissão docente, bem como a plasticidade identitária e o agir criativo que fundamentam a criação e a invenção do trabalho docente, tornando-o fonte de prazer (HÉLOU; LANTHEAUME, 2008). Nesse sentido, a partir de uma reflexividade e de experiências anteriores, os professores são os produtores dos saberes necessários à sua própria profissão, mesmo que não sejam reconhecidos enquanto tais (TARDIF; LESSARD; LAHAYE, 1991).

A valorização dos saberes, competências e práticas docentes passa também pelo seu estudo. Os princípios de justiça e as lógicas de ação desenvolvidos pela sociologia pragmática possibilitam a identificação e análise de situações reais do cotidiano dos professores e contribuem para a focalização da profissionalidade docente enquanto central para a construção de saberes e competências profissionais. Tal aporte teórico permitiu compreender que as lógicas de ação priorizadas em cada país não são restritas às situações escolares, mas trata-se de um princípio de ação que pode ser encontrado em outras dimensões sociais. Esse resultado chama a atenção para a dimensão cultural da prática docente de cada país, que só foi possível identificar a partir de uma abordagem baseada na educação comparada, analisando atuações de profissionais brasileiros e franceses.

Concluímos, assim, que a escolha da lógica de ação dos docentes depende de saberes e competências anteriores que são adquiridos, criados e construídos a partir das características próprias dessa profissão, do contexto institucional, cultural e político, da relação e interação com os colegas e alunos ou, enfım, a partir do processo de socialização profissional. Embora os processos de socialização profissional de cada país sejam distintos, identificamos critérios de justiça que são comuns às práticas dos docentes nos dois lados do Atlântico, que priorizam a escolarização dos alunos, buscam um conhecimento científico e legitimam a forma escolar. Denominamos essa forma de agir de lógica professoral que, constituída pelos e para os professores, permite compreender melhor a atividade docente por ser parte e parcela do processo de socialização profissional.

\section{Referências}

BOLTANSKI, LuC; CHIAPELLO, Ève. Le nouvel esprit du capitalisme. Paris: Gallimard, 1999.

BOLTANSKI, LUC; THÉVENOT, Laurent. De la justification: les économies de la grandeur. Paris: Gallimard, 1991.

DEROUET, Jean-Louis. École et justice: de l'égalité des chances aux compromis locaux? Paris: Éditions Métailié, 1992.

DUBAR, Claude. A socialização: construção das identidades sociais e profissionais. São Paulo: Martins Fontes, 2005.

DUBET, François. Injustiças: a experiência das desigualdades no trabalho. Florianópolis: UFSC, 2014. 
FRANCQ, Bernard. Introduction. In: FRANCQ, Bernard; MAROY, Christian. Formation et socialization au travail. Bruxelles: De Boeck \& Larcier, 1996. p. 7-19.

FREIRE, Paulo. Professora sim, tia não: cartas a quem ousa ensinar. São Paulo: Olho D'água, 1997.

GATTI, Bernardete Angelina et al. Professores do Brasil: novos cenários de formação. Brasília, DF: Unesco, 2019.

GAUTHERIN, Jacqueline. Quand la frontière est bien tracée... Éducation et Sociétés, Bruxelles, n. 16, p. 137-154, 2005.

HÉLOU, Christophe; LANTHEAUME, Françoise. Les difficultés au travail des enseignants: exception ou part constitutive du métier? Recherche et Formation, Lyon, n. 57, p. 65-78, 2008.

LANTHEAUME, Françoise. De la professionnalisation à l'activité, nouveaux regards sur le travail enseignant. Recherche et Formation, Lyon, n. 57, p. 9-22, 2008.

LANTHEAUME, Françoise. L'activité enseignante entre prescription et réel: ruses, petits bonheurs et souffrance. Education et Sociétés, Bruxelles, v. 19, p. 67-81, 2007.

LANTHEAUME, Françoise; SIMONIAN, Stéphane. La transformation de la professionnalité des enseignants: quel rôle du prescrit? Les Sciences de l'éducation: pour l'ère nouvelle, Paris, v. 45, p. 17-38, 2012.

MARTUCCELLI, Danilo. Existen individuos en el sur? Santiago de Chile: LOM, 2010.

MENARD, Charlène; VALENTE, Gabriela. Le concept de laïcité en France et au Brésil et ses conséquences pour l'éducation et la formation. In: COLLOQUE DOCTORAL INTERNATIONAL DE L'EDUCATION ET DE LA FORMATION, 2016, Nantes. Actes du colloque [... . Nantes: Cren, 2016.

NACHI, Mohamed. Introduction à la sociologie pragmatique. Paris: Armand Colin, 2012.

RESENDE, José Manuel. La reconnaissance publique des différences et de la justice scolaire: de la sociologie critique à la sociologie de la critique. Education et Sociétés, Bruxelles, n. 15, p. 137-152, 2005.

SETTON, Maria da Graça Jacintho. Socialização e cultura: ensaios teóricos. São Paulo: Annablume, 2012.

TARDIF, Maurice; LESSARD, Claude. Le travail enseignant au quotidien: expérience, interactions humaines et dilemmes professionnels. Bruxelles: De Boeck Université, 1999.

TARDIF, Maurice; LESSARD, Claude; LAHAYE, Louise. Os professores face ao saber: esboço de uma problemática do saber docente. Teoria e Educação, Florianópolis, n. 4, p. 215-233, 1991.

THÉVENOT, Laurent. Pragmatic regimes governing the engagement with the world. In: KNORR-CETINA, Karin; SCHATZKI, Theodore; SAVIGNY, Eike Von (org.). The practice turn in contemporary theory. London: Routledge, 2001. p. 1-29. Disponível em: http://gspm.ehess.fr/docannexe.php?id=543. Acesso em: 9 out. 2021. 
VALENTE, Gabriela Abuhab. As práticas docentes e a questão religiosa: elementos de comparação entre Brasil e França. 2019. Tese (Doutorado em Educação) - Faculdade de Educação, Universidade de São Paulo, São Paulo, 2019.

VINCENT, Guy. L'éducation prisonnière de la forme scolaire? Scolarisation et socialisation dans les sociétés industrielles. Lyon: Presses Universitaires de Lyon, 1994.

WITTORSKI, Richard; BRIQUET-DUHAZÉ, Sophie (org.). Comment les enseignants apprennent-ils leur métier? Paris: L'Harmattan, 2005.

ZANTEN, Agnès Henriot-Van et al. Quand l'école se mobilise les dynamiques professionnelles dans les établissements de banlieue. Paris: La dispute, 2002.

Recebido em: 30.12.2019

Revisado em: 30.06 .2020

Aprovado em: 04.08.2020

Gabriela Valente é doutora em educação pela Universidade de São Paulo e pela Université Lumière Lyon 2. Atualmente é professora temporária da Université Jean Jaurès - Toulouse II. Estuda temas que envolvem as práticas docentes, a diversidade sociocultural em escolas públicas e particulares e 0 acesso ao ensino superior na França. 